\section{Obstetric complications and affective psychoses}

\author{
Two case-control studies based on structured obstetric \\ records ${ }^{\dagger}$
}

M. BAIN, E. JUSZCZAK, K. McINNENY and R. E. KENDELL

\begin{abstract}
Background Unlike schizophrenia, little interest has been taken in the incidence of obstetric complications in affective psychoses.
\end{abstract}

\begin{abstract}
Aims To find out whether obstetric complications are more common in affective psychoses than matched controls.
\end{abstract}

Method Two hundred and seventeen probands with an in-patient diagnosis of affective psychosis who had been born in Scotland in 197|-74, and a further 84 born in 1975-78, were closely matched with controls and the incidence of obstetric complications in the two compared using obstetric data recorded in a set format shortly after birth.

\section{Results Abnormal presentation of the} foetus was the only complication significantly more common in the affective probands in the 1971-74 birth cohort and artificial rupture of the membranes was the only event more common in the probands in the 1975-78 cohort. Both are probably chance findings.

Conclusion It is unlikely that the incidence of obstetric complications is raised in people with affective psychoses of early onset.

\section{Declaration of interest Funding} from the Scottish Office Department of Health.

\footnotetext{
†See pp. 516-522 and pp. 527-530, this issue.
}

Over 30 case-control comparisons of the incidence of obstetric complications in people with schizophrenia and normal controls have been published in the past 20 years, and these have convinced many investigators not only that the incidence of obstetric complications is raised in schizophrenia, but also that they contribute to the aetiology of the syndrome. So far as we are aware, however, there has been no comparison of a substantial population of affective psychoses with normal controls based on obstetric information recorded at the time of birth. Lewis \& Murray (1987) studied large groups of patients with bipolar disorders and unipolar depression, but their obstetric information was derived from the routine case notes of adult psychiatric patients. Verdoux \& Bourgeois (1993) studied 23 patients with bipolar disorder and 23 normal controls, but their obstetric information was obtained retrospectively (by a non-blind interviewer) from the subjects' mothers. Rifkin et al (1994) compared 100 patients with schizophrenia and 67 with affective psychoses, but their information was also obtained retrospectively from the mothers and they had no normal controls. Done et al (1991) and Buka et al (1993) both studied large birth cohorts for whom extensive obstetric information had been recorded at the time and both identified which members of these birth cohorts had developed affective as well as schizophrenic illnesses in early adult life. However, their numbers of subjects with psychoses were small and neither obtained convincing evidence that the incidence of obstetric complications was raised in either schizophrenia or affective disorders, although Done et al (1991) did find a significantly reduced duration of pregnancy in their 32 subjects with affective psychoses. Our study was planned against this background. We also assumed that it was established that the incidence of obstetric complications was raised in schizophrenia, and likely that some of these complications contributed to the aetiology of schizophrenia. We wanted, therefore, to find out whether the aetiological role of intrauterine or perinatal trauma was specific to schizophrenia or whether it contributed to the genesis of affective psychoses as well.

\section{METHOD}

\section{Basic design}

The study was carried out alongside the study of obstetric complications and schizophrenia described by Kendell et al (2000, this issue) and the overall design of the two studies was almost identical. Briefly, it consisted of a case-control comparison based on subjects born in Scotland between 1 January 1971 and 31 December 1978. The obstetric data were derived from a cumulative register of all hospital births in Scotland (Scottish Morbidity Record 2, SMR2) containing fairly detailed demographic and obstetric information in a set numerical format, and members of the birth cohort who developed affective psychoses in adolescence or early adult life were identified from a register (Scottish Morbidity Record 4, SMR4) of all admissions to psychiatric hospitals or units in Scotland. Subjects with affective psychoses were individually matched with controls from the same birth cohort who had never been admitted to a psychiatric hospital with a discharge diagnosis of either schizophrenia or an affective psychosis on six different variables - the obstetric unit of birth, gender, date of birth ( \pm 2 months), maternal age ( \pm 2 years), maternal parity (first baby $v$. second or subsequent baby) and father's occupation (manual $v$. non-manual). Salient items in the SMR2 (obstetric) records of the probands and their controls were then compared. Further information is given in the previous paper describing the schizophrenia study (Kendell et al, 2000, this issue). As in Kendell et al's study, the 1971-74 and 1975-78 birth cohorts were analysed separately, mainly because the content and layout of the form used to record obstetric (SMR2) information was changed on 1 January 1975.

\section{Diagnostic criteria}

For most of the relevant time period the National Health Service (NHS) in Scotland recorded all hospital diagnoses by their ICD-9 code numbers (World Health Organization, 1978). For the purpose of this study 
it was therefore straightforward to define 'affective psychosis' as ICD-9 code numbers 296.0-296.9. It is important to note, though, that category 296 in ICD-9 corresponded to the Kraepelinian concept of manic-depressive psychosis, which embraced severe depressive illnesses whether or not they were accompanied by hallucinations or delusions as well as manic and bipolar illnesses. However, ICD-9 was replaced by ICD-10 (World Health Organization, 1992) on 1 April 1996 and this classification does not contain either a category of affective psychosis or a category corresponding to Kraepelin's manic-depressive psychosis. Nor is there any official translation from ICD-9 to ICD-10. For this reason affective psychosis had to be defined after 1
April 1996 by an arbitrary grouping of ICD10 codes (F30, F31, F32.2 and 32.3 and F33.2 and 33.3) chosen to correspond as closely as possible to the previous 296 code. Discharge rather than admission diagnoses were used throughout and in subjects with more than one psychiatric admission the most recent discharge diagnosis was used.

\section{Matching with controls}

SMR2 (obstetric) records were found for $343(51 \%)$ of the 668 subjects with affective psychoses born in 1971-78 originally identified from the SMR4 (psychiatric) file. The main reasons for failure to identify a matching SMR2 record were birth outside Scotland and domiciliary delivery. Vital demographic information (mainly the father's occupation) was missing from 26 obstetric records, which reduced the total available for matching from 343 to 317 . It proved possible to match all but 16 of these on all of the six variables described above. We therefore obtained 301 matched pairs -217 born in 1971-74 and 84 born in 1975-78. There are far fewer in the 1975-78 cohort because its members are, on average, 4 years younger and only just entering the risk period for the development of an affective psychosis.

At the time the SMR4 (psychiatric) data were extracted from the master file (October 1997) the age of the 1971-74 affective probands ranged from 22-26 years. Fifty per cent were male and $102(47 \%)$ had

Table I 1971-74 births. Complications of pregnancy, delivery and the puerperium. Comparison of probands with affective psychoses and their controls (217 matched pairs)

\begin{tabular}{|c|c|c|c|c|c|}
\hline & Affective probands & Controls & Odds ratio & $95 \% \mathrm{Cl}$ & $P$ value \\
\hline \multicolumn{6}{|l|}{ Dichotomous variables } \\
\hline Pre-existing maternal illness & 3 & 5 & 0.60 & $0.14-2.5 \mid$ & 0.48 \\
\hline \multicolumn{6}{|l|}{ Complications of pregnancy } \\
\hline Anaemia & 6 & 8 & 0.67 & $0.19-2.36$ & 0.53 \\
\hline Urinary infection & 7 & 6 & 1.20 & $0.37-3.93$ & 0.76 \\
\hline Haemorrhage & 9 & 8 & 1.14 & $0.4 I-3.15$ & 0.80 \\
\hline Rhesus antibodies & 4 & 8 & 0.50 & $0.13-2.00$ & 0.33 \\
\hline Abdominal or pelvic $X$-ray & 26 & 31 & 0.80 & $0.44-1.44$ & 0.46 \\
\hline Blood transfusion & 7 & 8 & 0.86 & $0.29-2.55$ & 0.78 \\
\hline Pre-eclampsia & 20 & 20 & 1.00 & $0.49-2.05$ & 1.00 \\
\hline Admission to hospital & 35 & 38 & 0.91 & $0.57-I .48$ & 0.71 \\
\hline Any complication' & 55 & 54 & 1.03 & $0.64-1.65$ & 0.90 \\
\hline \multicolumn{6}{|l|}{ Complications of delivery } \\
\hline Abnormal presentation & 17 & 7 & 2.67 & $1.04-6.81$ & 0.04 \\
\hline Artificial rupture of membranes & 80 & 98 & 0.66 & $0.43-1.01$ & 0.06 \\
\hline Oxytocics & 65 & 71 & 0.85 & $0.54-1.34$ & 0.49 \\
\hline Forceps delivery & 23 & 27 & 0.81 & $0.43-1.53$ & 0.52 \\
\hline Caesarean section & 22 & 15 & 1.47 & $0.76-2.83$ & 0.25 \\
\hline Non-spontaneous delivery & 52 & 47 & 1.18 & $0.71-1.95$ & 0.52 \\
\hline Baby small for gestational age & 12 & 15 & 0.80 & $0.37-1.71$ & 0.57 \\
\hline Birthweight $<2500 \mathrm{~g}$, gestation $<37$ weeks & II & 6 & 3.00 & $0.81-11.08$ & 0.10 \\
\hline Baby detained in hospital & 35 & 25 & 1.56 & $0.86-2.81$ & 0.14 \\
\hline Any complication' & 61 & 51 & 1.32 & $0.83-2.11$ & 0.24 \\
\hline \multicolumn{6}{|l|}{ Puerperium } \\
\hline Any complication' & 12 & 15 & 0.75 & $0.32-1.78$ & 0.51 \\
\hline \multicolumn{6}{|l|}{ Continuous variables (mean (s.d.)) } \\
\hline Antenatal haemoglobin $(g)$ & $11.33(1.18)$ & II.07 (I.17) & & $t=2.18$ & 0.03 \\
\hline Duration of pregnancy (weeks) & $39.16(2.74)$ & $39.58(2.15)$ & & $t=I .73$ & 0.08 \\
\hline Duration of labour (hours) & $7.63(5.86)$ & $7.91(6.18)$ & & $z=0.88$ & 0.38 \\
\hline Birthweight (g) & $3253(596)$ & 3287 (527) & & $t=0.63$ & 0.53 \\
\hline
\end{tabular}

I. These items represent the total number of (mostly rare) complications recorded on the Scottish Morbidity Record 2 form by their ICD-8 code numbers. For this reason they cannot be related to any combination of the other variables listed in the table. 
Table 2 1975-78 births. Complications of pregnancy, delivery and the puerperium. Comparison of probands with affective psychoses and their controls (84 matched pairs)

\begin{tabular}{|c|c|c|c|c|c|}
\hline & Affective probands & Controls & Odds ratio & $95 \% \mathrm{Cl}$ & $P$ value \\
\hline \multicolumn{6}{|l|}{ Dichotomous variables } \\
\hline Pre-existing maternal illness & 2 & 5 & 0.40 & $0.08-2.06$ & 0.27 \\
\hline \multicolumn{6}{|l|}{ Complications of pregnancy } \\
\hline Anaemia & 3 & 3 & 1.00 & $0.20-4.95$ & 1.00 \\
\hline Urinary infection & 2 & 2 & 1.00 & $0.63-15.99$ & 1.00 \\
\hline Haemorrhage & 3 & 6 & 0.40 & $0.08-2.06$ & 0.27 \\
\hline Pre-eclampsia & 10 & 15 & 0.62 & $0.26-1.48$ & 0.28 \\
\hline Admission to hospital & 12 & 18 & 0.57 & $0.24-1.36$ & 0.21 \\
\hline Any complication' & 27 & 30 & 0.82 & $0.4 I-I .67$ & 0.59 \\
\hline \multicolumn{6}{|l|}{ Complications of delivery } \\
\hline Abnormal presentation & 7 & 8 & 0.80 & $0.21-2.98$ & 0.74 \\
\hline Artificial rupture of membranes & 39 & 27 & 2.50 & $1.10-5.68$ & 0.03 \\
\hline Oxytocics & 35 & 28 & 1.64 & $0.77-3.46$ & 0.20 \\
\hline Breech delivery & I & 2 & 0.00 & $0.00-\infty$ & 1.00 \\
\hline Forceps delivery & 9 & 9 & 1.00 & $0.32-3.10$ & 1.00 \\
\hline Caesarean section - emergency or elective & 9 & 12 & 0.73 & $0.29-1.81$ & 0.49 \\
\hline Emergency Caesarean section & 2 & 6 & 0.20 & $0.02-1.7 \mid$ & 0.14 \\
\hline Non-spontaneous delivery & 21 & 23 & 0.83 & $0.36-1.93$ & 0.67 \\
\hline Apgar score 7 or 8 & 9 & 10 & 0.33 & $0.31-2.4 I$ & 0.80 \\
\hline Apgar score $<7$ & 4 & 2 & 2.00 & $0.37-10.92$ & 0.42 \\
\hline Baby small for gestational age & 5 & 6 & 0.83 & $0.25-2.73$ & 0.76 \\
\hline Birthweight $<2500 \mathrm{~g}$, gestation $<37$ weeks & I & 3 & 0.33 & $0.03-3.20$ & 0.34 \\
\hline Admission to Special Care Baby Unit & 13 & 18 & 0.64 & $0.28-1.49$ & 0.30 \\
\hline Any complication' & 20 & 22 & 0.88 & $0.43-1.79$ & 0.72 \\
\hline \multicolumn{6}{|l|}{ Puerperium } \\
\hline Any complication' & 7 & 7 & 1.00 & $0.29-3.45$ & 1.00 \\
\hline \multicolumn{6}{|l|}{ Continuous variables (mean (s.d.)) } \\
\hline Duration of pregnancy (weeks) & $39.83(1.34)$ & 39.36 (1.91) & & $t=\mathrm{I} .83$ & 0.07 \\
\hline Duration of labour (hours) & $7.63(5.26)$ & $6.95(5.24)$ & & $z=0.70$ & 0.48 \\
\hline Birthweight (g) & 3385 (49I) & $3245(554)$ & & $t=\mathrm{I} .73$ & 0.09 \\
\hline
\end{tabular}

I. These items represent the total number of (mostly rare) complications recorded on the Scottish Morbidity Record 2 form by their ICD-8 code numbers. For this reason they cannot be related to any combination of the other variables listed in the table.

manic or bipolar illnesses. The age of the 1975-78 probands ranged from 18-22 years. Fifty per cent were male and 45 (54\%) had manic or bipolar illnesses. Probands and controls were compared using the same standard case-control analysis of matched case-control sets as the parallel study of obstetric complications and schizophrenia (Kendell et al, 2000, this issue).

\section{RESULTS}

\section{7|-74 births}

The results of the proband-control comparisons are shown in Table 1 . The incidence of complications of both pregnancy and delivery is very similar in the affective probands and their controls. Indeed, there is only a significant difference between them for two of the 24 items studied. Abnormal presentation of the foetus is more common in the probands (17 v. 7; $P=0.04)$ and a maternal haemoglobin level below $10 \mathrm{~g}$ is more common in the controls (16 v. $7 ; P=0.05$ ). The mean maternal haemoglobin level is also $0.26 \mathrm{~g}$ lower in the controls $(P=0.03)$. As in the schizophrenia study, all the complications recorded on the SMR2 form by their ICD-8 (World Health Organization, 1967) code numbers were compared individually, but there was only one significant difference. Delivery complicated by malpresentation of the foetus was more common in the affectives (9v. $1 ; P<0.02)$, but this is really the same item as before.

\section{5-78 births}

The results of the proband-control comparisons are shown in Table 2. Again, the incidence of complications of both pregnancy and delivery is very similar in the affective probands and their controls - there is a significant difference between the two for only one of the (slightly different) set of 24 items studied. Artificial rupture of the membranes is more common in the probands (39 v. 27; $P=0.03$ ). It is important to note, though, that in the 1971-74 cohort artificial rupture of the membranes was more common in the controls $(98$ v. 80; 
$P=0.06$ ), suggesting that this is a chance finding. Similarly, abnormal presentation of the foetus is marginally more common in the control group (8v. 7) suggesting that the higher frequency in the probands in the 1971-74 birth cohort may also have been a chance finding.

As before, all the complications recorded on the SMR2 forms by their ICD8 code numbers were compared individually, but no significant differences emerged.

\section{DISCUSSION}

The most plausible explanation of these findings is that the incidence of obstetric complications is not raised in affective psychoses and that they are not a risk factor for the development of an affective psychosis. In both the 1971-74 and 1975-78 birth cohorts the incidence of complications of both pregnancy and delivery was very similar in the affective probands and their controls. The one complication that was significantly more common in the affective group in the 1971-74 cohort - abnormal presentation of the foetus - was marginally more common in the controls in the 197578 cohort and the only complication that was more common in the affective group in the 1975-78 cohort - artificial rupture of the membranes - was considerably more common in the controls in the larger 197174 cohort. Both complications are also different from those (emergency Caesarean section and a labour lasting over 12 hours) which were significantly more common in our probands with schizophrenia than in their controls (Kendell et al, 2000, this issue) and the reduced duration of pregnancy previously reported in their affective patients by Done et al (1991).

This conclusion is subject to two qualifications. First, none of the subjects even in the 1971-74 birth cohort was over the age of 26 years, so none had passed through the main risk period for the development of an affective psychosis. It is possible, therefore, that the incidence of obstetric complications is raised in the mainly unipolar or depressive psychoses presenting later in life. Second, the obstetric (SMR2) and psychiatric (SMR4) data on which this study was based were recorded, albeit in a set numerical format, in the course of ordinary clinical practice and little is known about their reliability (see Kendell et al, 2000, this issue). If their reliability was very low genuine proband-control differences could

\section{CLINICAL IMPLICATION}

It is unlikely that obstetric complications contribute to the aetiology of early onset affective psychoses.

\section{LIMITATIONS}

- Little information is available about the reliability of the routinely recorded obstetric data on which the study was based.

People with affective psychoses were identified by clinical diagnoses at the time of discharge from in-patient care.

Subjects were all under the age of 27 years, and so had not passed through the main risk period for affective psychosis.

M. BAIN, MFPHM, E. JUSZCZAK, MSc, K. McINNENY, BA, Information and Statistics Division, National Health Service in Scotland, Edinburgh; R. E. KENDELL, FRSE, Edinburgh University Department of Psychiatry, Royal Edinburgh Hospital, Edinburgh

Correspondence: Dr R. E. Kendell, 3 West Castle Road, Edinburgh EHIO 5AT

(First received 12 January 1999, final revision 25 October 1999, accepted 26 October 1999)

have failed to emerge. With a total sample size of over 300 matched pairs, however, it is unlikely that major differences could have been completely obscured, particularly as there was not even a trend for complications to be commoner in the affectives than in their closely matched controls.

\section{APPENDIX}

After this study was completed a very similar Swedish investigation was published by Hultman et a (1999). As here, this case-control study was based on a national birth cohort from the 1970s and obstetric information recorded shortly after birth. Affective psychosis was defined in the same way (ICD-9 category 296); the number of affective probands was smaller but still substantial $(n=198)$. Apart from a relationship with birth in January to April (the season of birth effect') the only obstetric variable that was significantly commoner in the affective psychoses than their controls was uterine atony (odds ratio $2.2,95 \% \mathrm{Cl}$ I.2-4.I), and when males and females were examined separately the difference was only significant in the former. This study therefore strengthens our conclusion that obstetric complications are unlikely to be a risk factor for the development of an early onset affective psychosis.

\section{REFERENCES}

Buka, S. L., Tsuang, M. T. \& Lipsitt, L. P. (1993)

Pregnancy/delivery complications and psychiatric diagnosis: a prospective study. Archives of General Psychiatry, 50, I5I-157.

Done, D. J., Johnstone, E. C., Frith, C. D., et al (199I) Complications of pregnancy and delivery in relation to psychosis in adult life: data from the British perinatal mortality survey sample. British Medical Journal, 302. 1576-1580.

Hultman, C. M., Sparén, P., Takei, N., et al (1999) Prenatal and perinatal risk factors for schizophrenia, affective psychosis, and reactive psychosis of early onset: case-control study. British Medical Journal, $3 \mathbf{3 1 8}$ $421-426$.

Kendell, R. E., McInneny, K., Juszczak, E., et al (2000) Obstetric complications and schizophrenia. Two case-control studies based on structured obstetric records. British Journal of Psychiatry, 176, 516-522.

Lewis, S. W. \& Murray, R. M. (1987) Obstetric complications, neurodevelopmental deviance, and risk of schizophrenia. Journal of Psychiatric Research, 2I, 4I3-42I.

Rifkin, L., Lewis, S., Jones, P., et al (1994) Low birth weight and schizophrenia. British Journal of Psychiatry, 165, 357-362.

Verdoux, H. \& Bourgeois, M. (1993) A comparative study of obstetric history in schizophrenics, bipolar patients and normal subjects. Schizophrenia Research, 9 67-69.

World Health Organization (1967) Manual of the International Statistical Classification of Diseases, Injuries and Causes of Death (ICD-8). Geneva: WHO.

- (1978) Mental Disorders: Glossary and Guide to their Classification in Accordance with the Ninth Revision of the International Classification of Diseases. Geneva: WHO.

- (1992) The ICD-10 Classification of Mental and Behavioural Disorders: Clinical Descriptions and Diagnostic Guidelines. Geneva: WHO. 